\title{
Plastid evolution: gene transfer and the maintenance of 'stolen' organelles
}

\author{
Eunsoo Kim and John M Archibald* \\ See research article http://www.biomedcentral.com/1471-2164/11/366
}

\begin{abstract}
Many heterotrophic organisms sequester plastids from prey algae and temporarily utilize their photosynthetic capacity. A recent article in BMC Genomics reveals that the dinoflagellate Dinophysis acuminata has acquired photosynthesis-related genes by horizontal gene transfer, which might explain its ability to retain 'stolen' plastids for extended periods of time.
\end{abstract}

The evolution of plastids - the light-gathering organelles of eukaryotic algae and plants - was a pivotal event in eukaryotic evolution. A number of eukaryotic lineages have acquired photosynthesis directly from cyanobacteria (that is, primary endosymbiosis) or indirectly via secondary or even tertiary endosymbiotic events involving eukaryotes in the role of both host and endosymbiont [1]. The dinoflagellates, a phylum of unicellular eukaryotes containing both photosynthetic and heterotrophic members, are the undisputed champions of plastid acquisition, having obtained plastids from phylogenetically diverse algal groups. Using the latest transcriptome sequencing technologies, Wisecaver and Hackett [2], in a paper recently published in BMC Genomics, provide fascinating insight into the genetics and cell biology of the dinoflagellate Dinophysis acuminata, an organism whose 'stolen' plastids appear to be serviced by nucleus-encoded proteins of diverse evolutionary origins.

\section{Acquired phototrophy in dinoflagellates}

Most photosynthetic dinoflagellates harbor canonical peridinin-pigmented plastids (of as yet unclear evolutionary origin), but a handful of species acquired their photosynthetic organelles from green algae, diatoms, and haptophytes [3]. Some heterotrophic dinoflagellates

*Correspondence: jmarchib@dal.ca

Canadian Institute for Advanced Research, Program in Integrated Microbial Biodiversity, Department of Biochemistry and Molecular Biology, Sir Charles Tupper Medical Building, Dalhousie University, Halifax, NS B3H 1X5, Canada also perform 'acquired phototrophy' by harboring photosynthetic endosymbionts or sequestering plastids from prey, a phenomenon known as kleptoplastidy [4]. Gymnodinium acidotum, for example, acquires transient plastids from cryptophytes, a phylum of small unicellular algae (Figure 1a). In addition to the plastid, the dinoflagellate retains the 'nucleomorph' (the secondary endosymbiont nucleus), mitochondrion, and in some cases the nucleus of the engulfed cryptophyte [5]. In contrast, the dinoflagellate Amphidinium wigrense possesses three membrane-bound transient plastids of cryptophyte origin but does not retain a nucleomorph or any other endosymbiont-derived organelles [6].

By hosting the plastids of other organisms, dinoflagellates that are otherwise heterotrophic can supplement their diet by utilizing fixed carbon and other compounds provided by photosynthetic plastids [4]. Predictably, the extent to which dinoflagellate hosts depend on acquired phototrophy increases as the availability of prey decreases. When food is limiting, D. acuminata can obtain 45 to $100 \%$ of its entire carbon budget from its cryptophyte-derived, photosynthetic plastids, a fraction that decreases to only 10 to $30 \%$ when prey is abundant [7]. The retention time of transient plastids in dinoflagellates varies greatly depending on the species involved and the conditions under which they are grown (Table 1). For instance, cryptophyte-derived plastids of Gymnodinium 'gracilentum' persist for only 1 to 2 days whereas those of Dinophysis caudata remain active for around 2 months $[8,9]$. Collectively, these observations underscore the significance of mixotrophy (the combination of phototrophy and heterotrophy) for the survival and proliferation of dinoflagellates living in changing environmental conditions, but do little to shed light on how the stolen organelles maintain functionality for extended periods of time.

\section{Plastids in Dinophysis}

The dinoflagellate genus Dinophysis is broadly distributed in the ocean and currently includes over 100 species, 


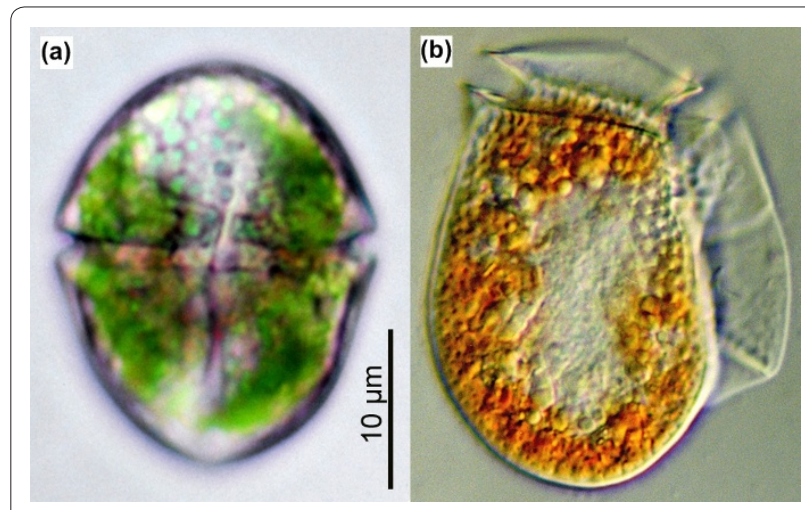

Figure 1. Light micrographs of the dinoflagellates Gymnodinium acidotum and Dinophysis fortii. (a) G. acidotum harbors blue-greencolored, transient plastids that are derived from a Chroomonas-like cryptophyte alga. (b) D. fortii periodically captures cryptophytederived, orange-colored plastids from the 'photosynthetic' ciliate Myrionecta rubra. Scale information for (b) is not available. A normal cell of $D$. fortii is typically 51 to $83 \mu \mathrm{m}$ long and 41 to $58 \mu \mathrm{m}$ wide. (a) Photo courtesy of Lee W Wilcox and Gary J Wedemayer; (b) photo courtesy of Kazuhiko Koike and Kiyotaka Takishita.

some of which pose major economic and health concerns as agents of diarrhetic shellfish poisoning. Dinophysis is well known for its ability to sequester and utilize functional plastids of cryptophyte and, less commonly, haptophyte origins [4]. Curiously, strains of Dinophysis appear incapable of harvesting plastids directly from the algal cells; they acquire them indirectly by engulfing the ciliate Myrionecta rubra, a heterotroph that itself feeds on cryptophytes belonging to the Teleaulax/Geminigera clade [8]. In M. rubra, the cryptophyte-derived plastids exist as chloroplast (plastid)-mitochondrial complexes $(\mathrm{CMCs})$, and one or more cryptophyte nuclei are retained separately from the CMCs in the ciliate host cytoplasm [4]. In contrast, cryptophyte-derived plastids of Dinophysis are bounded by two membranes and are devoid of nucleomorphs and mitochondria [8].

Whether or not the plastids of Dinophysis are permanent or transient has been the subject of much debate. Recent molecular data and culture experiments support the idea that Dinophysis plastids are most likely to be transient and need to be periodically 'replaced' by reuptake of photosynthetic M. rubra $[8,10]$. However, differences in the ultrastructure of Dinophysis plastids and those of free-living cryptophyte cells suggest to some researchers that Dinophysis consumes M. rubra not to replace its plastids, but rather to obtain growth factors and other essential compounds [4].

In the case of the dinoflagellates D. caudata and D. fortii, the acquired cryptophyte plastids remain functional for well over a month in the absence of the cryptophyte nucleomorph and nucleus $[8,11]$. This is remarkable given that present-day plastids possess at most around 200 protein-coding genes, a fraction of the coding capacity of their cyanobacterial progenitors, and are dependent on the import of hundreds of nucleusencoded proteins. Wisecaver and Hackett [2] surveyed the expressed gene set of $D$. acuminata in an effort to determine the extent to which its nuclear genome contains cryptophyte-derived genes for plastid-targeted proteins that could aid in the long-term stability of stolen plastids. In doing so, the authors took advantage of the 22-bp trans-spliced leader (SL) sequence present on mature dinoflagellate mRNAs, but not on those of ciliates or cryptophytes. D. acuminata poly(A)-primed cDNA was amplified using a 5' SL primer and sequenced using ultra-high-throughput 454 pyrosequencing. To control for the possibility of contamination, the transcriptomes of the ciliate M. rubra and the cryptophyte Geminigera cryophila, the organisms from which $D$. acuminata acquires its plastid, were also surveyed. The results are significant for two main reasons.

First, from a set of approximately 6,000 unique gene clusters, Wisecaver and Hackett [2] identified only five dinoflagellate nuclear genes that were strong candidates for being plastid-related - $p s b U$, petF, and $p s b M$ and genes for the light-harvesting protein LI818 and the triose-phosphate transporter TPT. As predicted, the protein products of these five genes possess putative transit peptides: that is, amino-terminal leader sequences that are required to translocate host-synthesized proteins

Table 1. Retention time of transient plastids in dinoflagellates under laboratory conditions

\begin{tabular}{lll}
\hline Dinoflagellate host & Source of transient plastids & Retention time \\
\hline Dinophysis caudata & Teleaulax sp. (cryptophyte) ${ }^{1}$ & Around 2 months \\
Dinophysis fortii & Teleaulax amphioxeia (cryptophyte) ${ }^{1}$ & At least 40 days \\
Gymnodinium acidotum & Chroomonas sp. (cryptophyte) & At least 10 days \\
Gymnodinium 'gracilentum' & Rhodomonas salina (cryptophyte) & $1-2$ days \\
Pfiesteria piscicida & Rhodomonas sp. (cryptophyte) & At least 9 days ${ }^{2}$ \\
Unnamed dinoflagellate & Phaeocystis antarctica (haptophyte) & 5-8 months \\
\hline
\end{tabular}

${ }^{1} D$. caudata and $D$. fortii cannot sequester plastids directly from the cryptophyte cells, and instead obtain them from the ciliate Myrionecta rubra that consumes cryptophytes.

${ }^{2}$ Retention time varies depending on light intensity. 
across the two inner plastid membranes in other algae [1]. D. acuminata thus appears to possess significantly fewer plastid-related genes in its nucleus than do dinoflagellates with permanent plastids, suggesting that transfer of additional genes for plastid-targeted proteins must occur if the stolen plastids are to be fully integrated into the host dinoflagellate. Second, sequence analyses reveal that only one of the plastid-related genes identified in D. acuminata ( $p s b M)$ actually comes from the same source as its stolen plastid - that is, cryptophyte algae. The remaining four genes appear to have been acquired by horizontal gene transfer from other sources, including haptophytes and fucoxanthin-containing dinoflagellates [2].

The results of Wisecaver and Hackett [2] are particularly interesting when contrasted with the evolution of kleptoplastidy in the sea slug Elysia chlorotica, an organism that harvests plastids from the stramenopile alga Vaucheria litorea [12]. The transient plastids of E. chlorotica remain remarkably stable for up to 10 months in the absence of the algal nucleus. Recent studies have uncovered a number of genes for putative plastidtargeted proteins in the sea-slug nucleus, such as $p s b O$ (for photosystem II) and $f c p$ (for light-harvesting complexes) [12]. These sea-slug genes have uniformly high sequence identities to homologs in $V$. litorea, suggesting that the genes were transferred relatively recently from the algal nucleus. This is in stark contrast to the situation in D. acuminata, whose putative plastidtargeted proteins have been acquired from multiple algal sources. This difference is perhaps explained by the trophic strategy of $D$. acuminata, which, in contrast to E. chlorotica, consumes a variety of prey, including many different photosynthetic algae, while performing acquired phototrophy. Exactly when $D$. acuminata acquired these 'foreign' genes is unclear. Some or all heterotrophic dinoflagellates are thought to be ancestrally photosynthetic [1], and so at least some of them might be holdovers from a time when Dinophysis species harbored more conventional plastids.

The advent of ultra-high-throughput sequencing has made it possible to obtain massive sequence datasets from experimentally challenging organisms - and even collections of intimately associated organisms - on a scale unimaginable even a few years ago. The results of Wisecaver and Hackett [2] represent a landmark in this regard, providing an important launch point for future dissection of the molecular and biochemical processes involved in dinoflagellate kleptoplastidy. Such experimentation will include definitive proof that the gene products in question are indeed targeted to the plastids in the context of $D$. acuminata cells, and even deeper transcriptome sequencing to further assess the degree of plastid proteome mosaicism in these intriguing organisms.

\section{Acknowledgements}

We thank LW Wilcox, LE Graham, and JD Hackett for comments on an earlier version of this article.

Published: 10 June 2010

\section{References}

1. Sanchez-Puerta MV, Delwiche CF: A hypothesis for plastid evolution in chromalveolates. J Phycol 2008, 44:1097-1107.

2. Wisecaver JH, Hackett JD: Transcriptome analysis reveals nuclear-encoded proteins for the maintenance of temporary plastids in the dinoflagellate Dinophysis acuminata. BMC Genomics 2010, 11:366.

3. Hackett JD, Anderson DM, Erdner DL, Bhattacharya D: Dinoflagellates: a remarkable evolutionary experiment. Am J Bot 2004, 91:1523-1534.

4. Johnson MD: The acquisition of phototrophy: adaptive strategies of hosting endosymbionts and organelles. Photosynth Res 2010, in press.

5. Fields SD, Rhodes RG: Ingestion and retention of Chroomonas spp. (Cryptophyceae) by Gymnodinium acidotum (Dinophyceae). J Phycol 1991, 27:525-529.

6. Wilcox LW, Wedemayer GJ: Dinoflagellate with blue-green chloroplasts derived from an endosymbiotic eukaryote. Science 1985, 227:192-194.

7. Riisgaard K, Hansen PJ: Role of food uptake for photosynthesis, growth and survival of the mixotrophic dinoflagellate Dinophysis acuminata. Mar Ecol Prog Ser 2009, 381:51-62.

8. Park MG, Park JS, Kim M, Yih W: Plastid dynamics during survival of Dinophysis caudata without its ciliate prey. J Phycol 2008, 44:1154-1163.

9. Skovgaard A: Role of chloroplast retention in a marine dinoflagellate. Aquat Microb Ecol 1998, 15:293-301.

10. Takishita K, Koike K, Maruyama T, Ogata T: Molecular evidence for plastid robbery (kleptoplastidy) in Dinophysis, a dinoflagellate causing diarrhetic shellfish poisoning. Protist 2002, 153:293-302.

11. Nagai S, Nitshitani G, Tomaru Y, Sakiyama S, Kamiyama T: Predation by the toxic dinoflagellate Dinophysis fortii on the ciliate Myrionecta rubra and observation of sequestration of ciliate chloroplasts. J Phycol 2008, 44:909-922.

12. Rumpho ME, Worful JM, Lee J, Kannan K, Tyler MS, Bhattacharya D, Moustafa A, Manhart JR: Horizontal gene transfer of the algal nuclear gene $p s b O$ to the photosynthetic sea slug Elysia chlorotica. Proc Natl Acad Sci USA 2008, 105:17867-17871.

13. Lewitus AJ, Glasgow HB, Burkholder JM: Kleptoplastidy in the toxic dinoflagellate Pfiesteria piscicida (Dinophyceae). J Phycol 1999, 35:303-312.

14. Gast RJ, Moran DM, Dennett MR, Caron DA: Kleptoplasty in an Antarctic dinoflagellate: caught in evolutionary transition? Environ Microbiol 2007, 9:39-45.

\section{doi:10.1186/1741-7007-8-73}

Cite this article as: Kim E, Archibald JM: Plastid evolution: gene transfer and the maintenance of 'stolen' organelles. BMC Biology 2010, 8:73. 